\title{
Production Technology of the Internal Combustion Engine Crankcase Using Additive Technologies
}

\author{
Anton V. Agapovichev ${ }^{1}$, Andrei V. Balaykin ${ }^{1}$ \& Vitally G. Smelov ${ }^{1}$ \\ ${ }^{1}$ Samara State Aerospace University, Samara, Russia \\ Correspondence: Anton V. Agapovichev, Samara State Aerospace University, Samara, Russia.
}

Received: November 8, 2014

Accepted: November 16, $2014 \quad$ Online Published: March 30, 2015

doi:10.5539/mas.v9n4p335

URL: http://dx.doi.org/10.5539/mas.v9n4p335

\begin{abstract}
The use of rapid prototyping technologies to create new industrial products, of particular importance is the cost and speed of production, a unique opportunity to use cost-effective methods for the production of parts by investment casting. At the stage of pilot production, which is characterized by frequent changes in design, the problem of the rapid production of cast components becomes crucial. This is mainly due to the complexity of manufacturing foundry equipment. In turn, the research and development of rapid prototyping technologies have allowed a new level of optimization and the introduction of new technologies in the investment casting. The purpose of the given work consists in estimations of efficiency of application of technology of fast prototyping at moulding on melted models, estimations of accuracy of the received sizes of casting at moulding on melted models with use of technology of fast prototyping, and also an estimation of adequacy of virtual modelling of process of moulding in comparison with real process of pouring. The work was conducted with the use of cross-cutting design in CAM / CAD / CAE systems. The study size and precision parameters of the casting was conducted in co-ordinate measuring machine. The work has been verified the adequacy of the virtual simulation of the process of forming a casting in the casting simulation ProCAST, in comparison with those obtained castings. The study showed that the use of rapid prototyping technologies with investment casting can significantly reduce the time for making castings, decrease production costs and improve the accuracy of the casting size.
\end{abstract}

Keywords: additive technology, rapid prototyping, silicone mold, wax model, plaster form

\section{Introduction}

Foundry is one of the most important branches of engineering. In various designs of modern machines and devices, about $60-80 \%$ of the parts according to their weight are cast of steel, iron, copper, aluminum, magnesium and their alloys (Cheah et al., 2005).

Foundry owes its advantages over other methods for producing blanks (Onuh \& Yusuf, 1999). Using different methods of molding, we can obtain articles of complex configuration from any metals and their alloys. Most of these cannot be obtained, for example by stamping, forging or machining (Griffiths, 1993).

In order to save time and resources for the design, as we as for the development and manufacture of products, promising is the use of new technological processes in blanking and main manufacture (Hopkinson et al., 2006).

The use of rapid prototyping technology allows to receive high-quality and relatively inexpensive models, spending few hours for their production, and not days or weeks as it is with traditional methods (Sun, C. et al., 2014).

Small size, presence of thin-walled elongated cells and slotted channels of complex shape makes it difficult to obtain details using traditional methods of production (Vaezi et al., 2011).

The article considers production of engine crankcase by investment casting (IE) using rapid prototyping (Chica et al., 2013).

IE method with the advantages compared to other methods for producing castings, is widespread. This method provides a cast alloy of any complex shape castings, which weights from a few grams to tens of kilograms with walls of thickness less than $1 \mathrm{~mm}$ (Kaplas, M. \& R. Singh, 2008).

IE method takes a lot of time in mind of the technological difficulties associated with obtaining accurate master 
models and pouring wax models, providing reception of complex profiles with high geometric precision. At the same time, the method IE is one of the most efficient in creating complex shapes made of metal, and in some cases - and the only possible method of casting, for example, when items have undercuts, thin walls or complex configuration.

These features enable the method to approximate the castings of the finished part, and in some cases to get a cast item, additional processing of which is not required prior to assembly (Yan et al., 2009). This greatly reduces the complexity and cost of manufacturing parts, decreases metal consumption, saves energy, etc (Pham, D.T. and R.S. Gault, 1998).

The investment casting technology provides the possibility to produce complex thin-walled structures, combine different items in the nodes, reducing the weight and size of products, create details (for example, cooled blades with complex labyrinth cavities of gas path) unattainable by other methods (Balyakin, A.V. et al., 2012).

But the method of IE takes a lot of time due to technological difficulties associated with obtaining accurate master models and pouring wax models, providing reception of complex profiles with high geometric precision (Zybanov, S. V. et al., 2009).

Speeding up the process of investment casting should improve performance of the details' manufacturing process (Dimitrov, D. et al., 2006). However, this should not allow reducing geometric accuracy of the product. Additive Technology Laboratory is a division of the center for collective use "Interdepartmental Academic Research and Production Center of SAM-technologies" (CCU «CAM-technology").

Equipment installed in the laboratory produces prototypes of products, the master - models, precision parts, according to the available 3D models in the shortest time with high quality features. Objet 3D Printer 350 of Israeli firm EDEN has a field for printing products sized $350 \mathrm{~mm}$ by $350 \mathrm{~mm}$ and depth of $200 \mathrm{~mm}$, printing accuracy is up to 16 microns.

The main difference between rapid prototyping technologies and standard approach is as follows (Singh, R. and J.P. Singh, 2009):

- The use of CAD / CAM / CAE systems;

- The cost and time of preparation is much lower than the standard approach (about 5 times);

- The number of cycles of tooling use is much lower than with the standard approach.

\section{Materials and Methods}

The details' manufacturing process consists of the following steps:

- digitization of detail or its surface modeling, including construction of a 3D model in the CAD system;

- modeling of the technological processes of casting of billet in CAE system;

- growing master-model and internal signs of the product from photo-polymeric plastic on a 3D printer;

- producing casting forms of silicone using master model;

- pouring gypsum plate in the form of silicone and its heat treatment;

- pouring wax into silicone mold;

- covering models into plaster shell and removing wax;

- casting metal in plaster shell;

- removing the plaster shell and internal mark, cropping and trimming gating supply system;

- heat-treatment of castings;

- controlling the resulting preform detail.

It is necessary to build in the CAD system a three-dimensional model for obtaining master models or prototypes of the product. In order to construct 3D models of parts we used computer aided design with manufacturing and engineering analysis (CAD / CAM / CAE) NX (Figure 1) from Siemens PLM Software. 


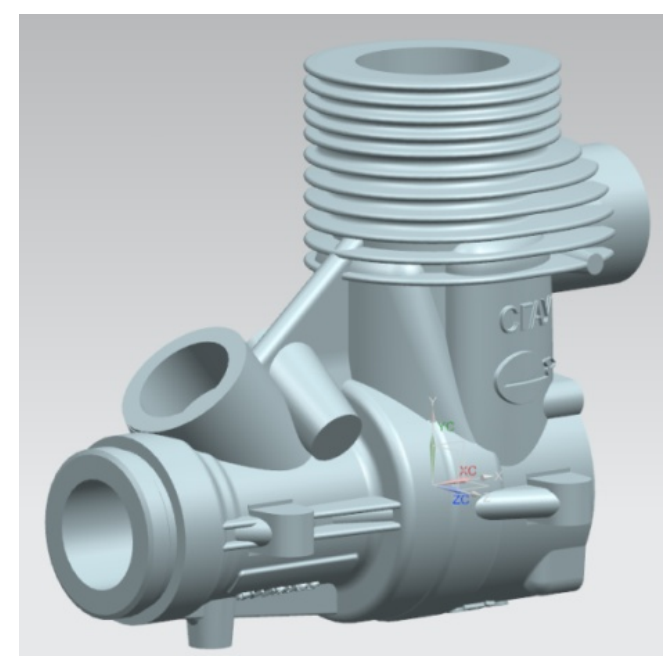

Figure 1.3D model of the engine crankcase

After constructing a 3D model of a part we built 3D a model of the work piece (Figure 2) by adding the allowance for subsequent machining, by adding the necessary technological gains and bases, and forming the supply gating system.

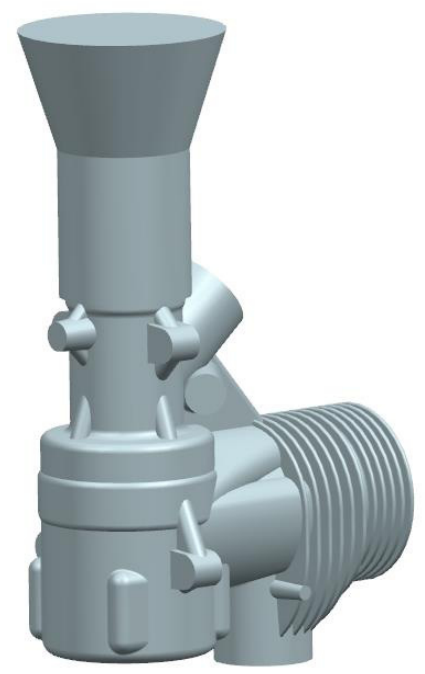

Figure 2. 3D-model of the work piece

In this step, a future billet of the details is enlarged considering the shrinkage factor of the material. Correction factor of the photopolymer master model is the sum of the coefficients of shrinkage of wax and metal.

Before growing the master model, manufacturing silicone molds and pouring wax, a virtual simulation of the forming billet was performed in CAE system of foundry simulation ProCast.

ProCAST isa foundry simulation system, providing a joint solution of temperature, hydrodynamic and deformation problems with unique opportunities of studying all possible processes of casting of foundry alloys. An additional advantage of ProCAST is that it is possible to calculate the stress, microstructure and model more exotic casting processes (Vdovin, R.A., 2012).

Some critical conditions, such as cold form, low filling speed or low casting temperature may cause defects with completing the form. ProCAST predicts when and where there may be filling or cold shuts, porosity, shrinkage voids, air bubbles (Futas \& Pribulova, 2013). All the necessary design changes can be verified with minimal 
costs, directly on the computer.

Modeling in CAE system allows to optimize the runner feeding system (RFS), perform virtual casting (see Figure 3) and, as a result, minimize the appearance of spoilage in casting billets, abandon the test fills and get satisfactory details in minimal time (Li, $\mathrm{H}$ et al., 2014).

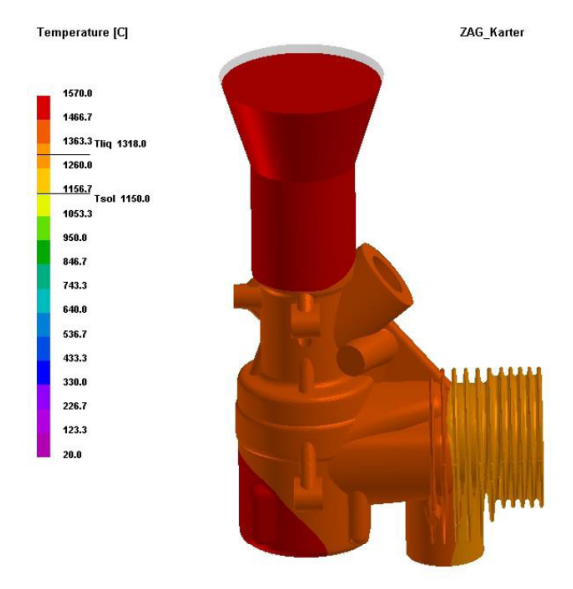

Figure 3. Modeling the process of filling the shell mold and the temperature distribution of the melt in CAE system ProCast

Then printing prototypes of products was done on a 3D printer. Placing the work model of the crankcase in the output tray of the 3D printer is shown in Figure 4.

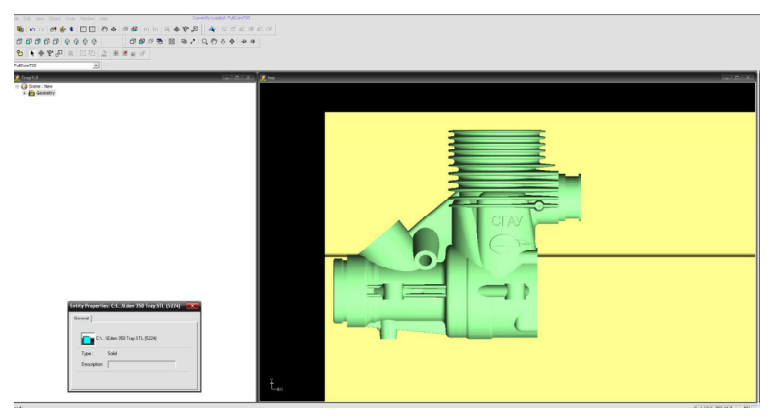

Figure 4. Placing the work model of the crankcase in the output tray of the $3 \mathrm{D}$ printer

After positioning the pattern on the output tray we calculated the necessary amount of support material, base material, and printing time. For growing model of the 3D printing system Eden we require 75 grams of base material (FullCure 720) and 122 grams (FullCure 705) of material support, and the printing would take 4 hours and 50 minutes.

As a result we got a prototype of an internal combustion engine thrust $2 \mathrm{hp}$ with $3 \mathrm{D}$ printing system Objet Eden 350, using a multi-jet technology of material application and the curing layer with a UV lamp (Figure 5).

Then we remove the support material (FullCure 705) using a jet of water under pressure in the water purification unit Objet WaterJet. 


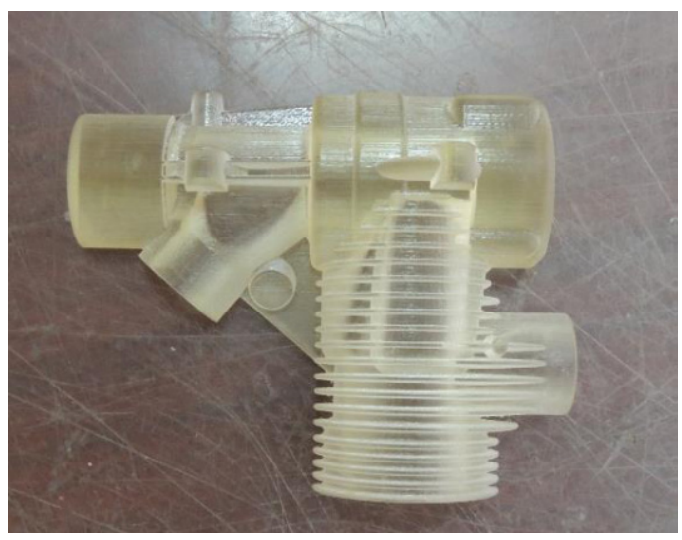

Figure 5. Master model obtained by 3D printer Objet 350

The master model, made on the 3D printer, was used to obtain the elastic form of their silicone compound. Products are tested to be free from defects (scratches and chips). Before using the geometry, each master model is tested at the gauging machine (Gill, S. S. \& M. Kaplas, 2009).

The use of silicone allows getting models of wax and plaster of any complexity: undercut with a complex parting surface, with different inserts. Reproduction of complex forms in smallest detail is possible.

First the preparation of the master model is implemented; gating of feeding system is created by gluing rods of different diameters to the master model, thus creating different parts of the gating- supply system. Also, if necessary, a parting surface is formed (Figure 6). Then a mold box for casting silicone is made.

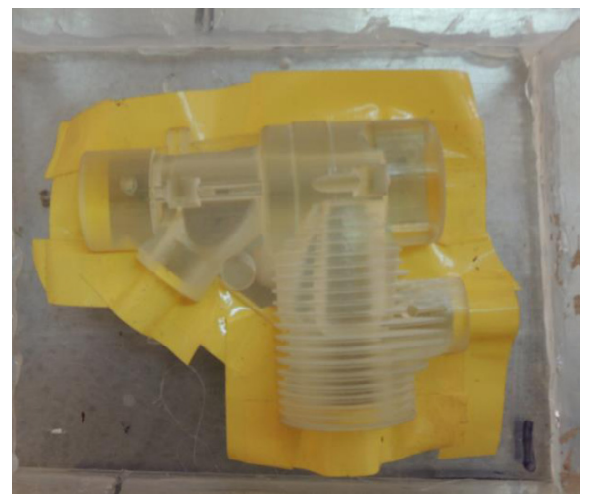

Figure 6. Formation of the parting surface

After that, mixing and degassing of the silicone is carried out. We used clear silicone compound of LasilT brand with a platinum catalyst for production of silicone forms. To obtain a high-quality silicone mold, it is necessary to carry out its evacuation after mixing and before pouring the silicone. This allows to remove the air from the silicone rubber and to eliminate the occurrence of defects on the surface of the models. Degassing silicone washer formed in the vacuum system MTT 5 / 04s with exposure in a vacuum for 20 minutes. Then the silicone was casted into the molding box.

After hardening, the resulting silicone mold is cut into two parts (Figure 7), by a wavy line, the master model is extracted. 


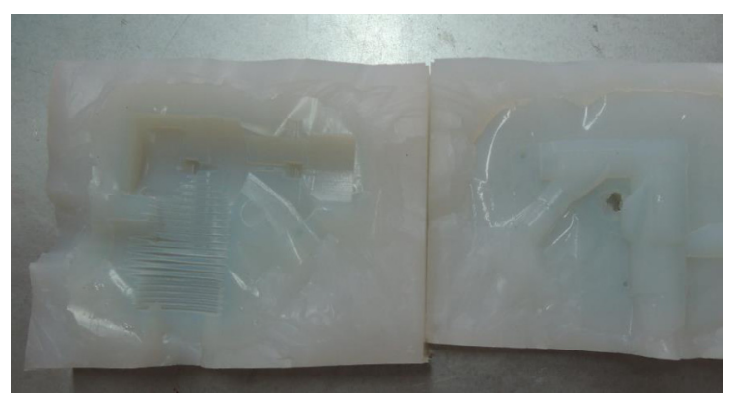

Figure 7. Silicone molds

In our center we use a technique that we have developed - technique of designing and manufacturing silicone molds using different methods of forming surfaces of the connector, formation of internal cavities and alignment of the various characters.

Casting models of wax in a vacuum into flexible forms allows getting prototypes and small batches of details of any complexity and without manufacturing traditional technological equipment (Jones \& Yuan, 2003).

Through the use of a wide range of materials, castable copies may be flexible, rigid, heat-resistant, ultraviolet-resistant, transparent and/or of different colors, as well as waxen. For such casting we use special two-component polymers, cast in flexible forms in vacuum. After hardening, the physical and mechanical properties of these polymers are identical to those of traditional thermoplastic plastics (ABS, PS, PP, etc.). Bicomponent compositions that mimic the properties of different elastomers are also available. To produce wax models we use special modeling waxes (Bassoli, E. et al., 2007).

A wax model of the crankcase is shown in Figure 8. The internal cavity of the model was created by insertion and alignment of gypsum marking the elastic form fully simulating the internal cavity of the crankcase. The internal mark is obtained by pouring gypsum in a flexible form, and its subsequent heat treatment.

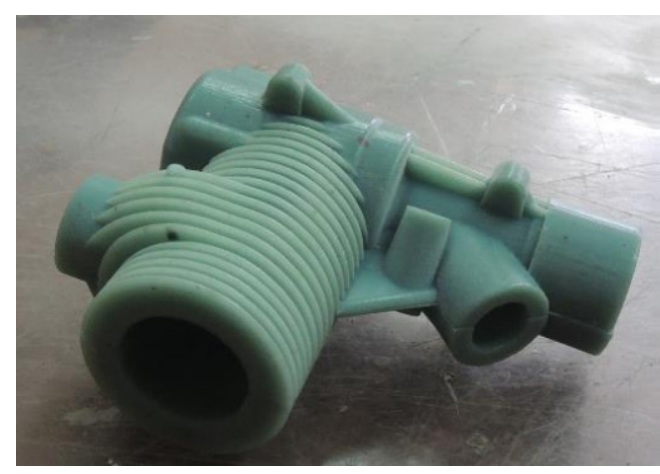

Figure 8. Wax model crankcase

For casting aluminum alloys, the forms are made of plaster. The use of modern materials, as well as water-based binder, sands allows creating high-quality forms and achieving a minimum allowance and high surface quality.

Thin-walled castings can be produced in plaster molds, as gypsum can be heated to a temperature of 600 to $700{ }^{\circ} \mathrm{C}$ without damage. Such heating contributes to a better filling of narrow cavities in the mold with the liquid metal. One of the valuable properties of plaster and molding materials based on it is the ability to give a smooth and clean print. This ability is retained even when the mixture is with coarse sands. The addition of asbestos in plaster dramatically reduces the number of cracks while drying and calcination of the form.

At a temperature of $150 \pm 5{ }^{\circ} \mathrm{C}$, the wax gating system and the model itself are made of plaster shells. Gypsum shell should be heated to temperatures of wax melting as soon as possible. To accelerate heating, a preheated oven is used.

Gypsum shell is left for 2 hours at $950{ }^{\circ} \mathrm{C}$, and then the door of the furnace is opened slightly for 20-30 minutes 
to add a sufficient amount of air. Then it is held for another two hours to complete the melting of the model.

Thereafter, the shell is cooled and slag is removed, though some quantity of it can be present in the shell. The casing is then calcined again and the metal is cast into it.

The metal was melted in an induction furnace. Casting the metal was carried out by the developed technology.

After pouring the gypsum model is removed by washing it in water. After the destruction of the shell and cleaning the remnants of plaster a perfect product was received (see Figure 9).

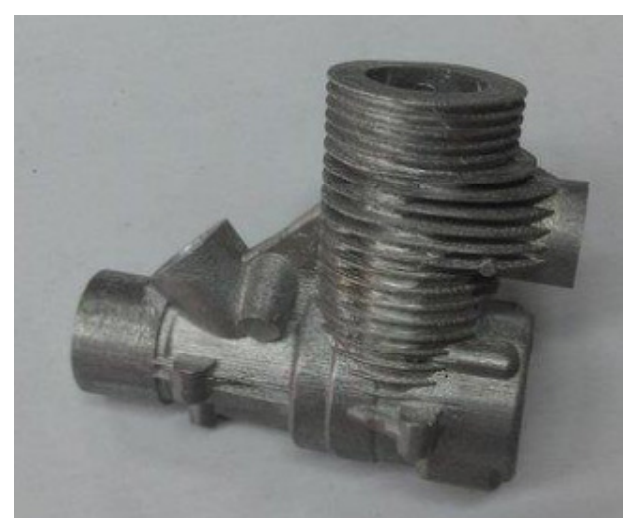

Figure 9. Casting crankcase

\section{Results}

Determined is the quality of the casting size, surface roughness, structure, mechanical and physical properties of the metal, as well as the presence or absence in the casting of internal and external defects such as voids, blockages, cracks, etc.

Technology for producing castings affects their quality and, consequently, defines the principles that should be followed in the design.

The advantages of the method of investment casting using additive techniques may be implemented, if the casting for the production manufacturable by this method. A tech is the design of the molded part, in which you can make a casting that meets the requirements of accuracy, surface roughness, physical and mechanical properties and structure of the metal with the least expenditure of time and money (Ivanov V.N. et al., 1984)

Dimensional accuracy is evaluated by the actual deviations from the nominal size of the casting. In our case, the dimensional accuracy of the resulting casting was tested for co-ordinate measuring machine. All dimensions are made in tolerance. Measured above-obtained casting results are soot-related with technical requirements.

The analysis has shown that the microstructure of a regional zone of the sample represents $\alpha$ grains - of firm solution, particle of silicon, phase $\mathrm{AlSiBe}_{3}$ and $\mathrm{Al}_{3} \mathrm{Ti}$, and also an iron impurity $\mathrm{AlFeBe}$ of size with $0,5-0,6 \mathrm{~mm}$. On distance from edge about $0,8 \mathrm{~mm}$ the beginning of a thin disperse zone in width of $0,4-0,5 \mathrm{~mm}$ in which the sizes of the allocated phases make $0,1-0,2 \mathrm{~mm}$ is observed. In process of deepening the zone with various dispersion of phases from 0,1 to $0,2 \mathrm{~mm}$ deep was observed. These values correspond to the values received by a way of modelling in CAE system.

The use of rapid prototyping technology in conjunction with the method of investment casting allowed us to get good, high-quality castings of complex, thin-walled parts in a short time and with minimal technological training.

\section{Discussion}

Modern economic conditions have led to considerable reduction of volumes of output both in aviation branch as a whole, and in aviation engine building in particular that has caused appreciable changes of technology and the manufacture organisation. Besides, an exit domestic aviation engine building on the world markets and participation in the international cooperation of creation of aviation technics necessity of rapprochement, or harmonisation of processes of creation of aviation technics, including dictate technologies, with the foreign aviation technics. Complex application of information technology at creation of foreign aviation technics 
demands transition to them and domestic aviation engine building (Balyakin, A.V. et al., 2012).

Machining processes in the production of aerospace components Profile require considerable time.

To save material and time resources for the design, development and manufacture of parts promising is the use of rapid prototyping technology.

This article describes the technology of parts production by investment casting using rapid prototyping technology, which allows a short time to work out details of varying difficulty through the production technology, to produce thin-walled parts of complex shape without using sophisticated equipment.

The computer analysis of foundry processes allows essentially optimise foundry processes, save time and material resources. At a design stage of technology of moulding (before manufacturing forms) allows to minimise possible miscalculations and the errors inevitably arising in the course of working out to lower financial and time expenses to raise efficiency, competitiveness, quality and reliability of developed production (Vdovin, R.A., 2012).

\section{Conclusion}

The development of new product samples is of particular importance for speed prototyping.

This applies particularly to the manufacture of cast components, which are often the most difficult and time-consuming part of the production. This is mainly due to the high cost of master models and foundry tooling.

From the moment of the release of the design to mass production of a new product undergoes a lot of changes, each of which needs to be corrected or modified by applicable tooling. In such circumstances, this tooling is single and is not used in the future mass production. In this regard, the traditional methods of foundry parts, pilot production, are extremely time-consuming, not to mention the financial cost.

The transition to digital product description (CAD), together with the use of additive technology has enabled a new level of foundry. Departure from traditional technologies, the use of technologies for the production of master models by layering synthesis possible to significantly reduce the time to create new products.

When using additive technologies created, the entire life cycle of products takes place in a single technological chain of CAD / CAM / CAE systems. Using a single technological chain in modern experimental, foundries can significantly reduce the time and cost for prototyping and prototypes of new products.

By means of use of additive technologies it was possible to reduce essentially term of manufacturing of a detail, to cut down expenses on equipment manufacturing, to raise production efficiency. It, finally, has led to reduction of time of an appearance of a complete product on the market.

A further area of research related to the identification of the relationship between the properties derived from parts of their production technology that will allow giving further details of the desired properties.

\section{Acknowledgement}

This work was financially supported by the Government of the Russian Federation (Ministry of Education and Science of the Russian Federation) by decree number 218 of 09/04/2010 (code theme 2013-218-04-4777).

\section{References}

Balyakin, A. V., Smelov, V. G., \& Chempinsky, L. A. (2012). Additive technology application details of combustion. Vestnik of the Samara State Aerospace University, 3-2(34), 47-52. ISSN: 1998-6629.

Bassoli, E., Gatto, A., Iuliano, L., \& Violante, M. G. (2007). 3D printing technique applied to rapid casting. Rapid Prototyping Journal, 13, 148-155. http://dx.doi.org/10.1108/13552540710750898

Cheah, C. M., Chua, C. K., Lee, C. W., Feng, C., \& Totong, K. (2005). Rapid prototyping and tooling techniques: A review of applications for rapid investment casting. International Journal of Advanced Manufacturing Technology, 25, 308-320. http://dx.doi.org/10.1007/s00170-003-1840-6

Chica, E., Agudelo, S., \& Sierra, N. (2013). Lost wax casting process of the runner of a propeller turbine for small hydroelectric power plants. Renewable Energy, 60, 739-745. http://dx.doi.org/10.1016/j.renene.2013.06.030(60)

Dimitrov, D., Schreve, K., \& De Beer, N. (2006). Advances in three dimensional printing - State of the art and $\begin{array}{lllll}\text { future perspectives. Rapid } & \text { Prototyping }\end{array}$ http://dx.doi.org/10.1108/13552540610670717

Futas, P., \& Pribulova, A. (2013). Computer simulation of casting produced by investment casting technology. 
International Multidisciplinary Scientific GeoConference Surveying Geology and Mining Ecology Management. SGEM, 1, 29-36. http://dx.doi.org/10.5593/SGEM2013/BB2.V1/S07.004

Gill, S. S., \& Kaplas, M. (2009). Comparative study of 3D printing technologies for rapid casting of aluminium alloy. Materials and Manufacturing Processes, 24(12), 1405-1411. http://dx.doi.org/10.1080/10426910902997571

Griffiths, M. (1993). Rapid prototyping options shrink development costs. Modern Plastics, 70, 45-47. ISSN: 00268275 .

Hopkinson, N., Hague, R. J., \& Dickens, P. M. (2006). Rapid Manufacturing: An Industrial Revolution for the Digital Age. John Wiley \& Sons, Ltd, ISBN: 0470016132;978-047001613-8, pp: 1-285.

Ivanov, V. N., Kazennov, S. A., \& Kurchman, B. S., et al. (1984). Investment Casting (3nd ed.). Moscow, M: Mashinostroenie.

Jones, S., \& Yuan, C. (2003). Advances in shell moulding for investment casting. Journal of Materials Processing Technology, 135, 258-265. http://dx.doi.org/10.1016/S0924-0136(02)00907-X

Kaplas, M., \& Singh, R. (2008). Experimental investigations for reducing wall thickness in zinc shell casting using three-dimensional printing. Proceedings of the Institution of Mechanical Engineers, Part C: Journal of Mechanical Engineering Science, 222(12), 2427-2431. http://dx.doi.org/10.1243/09544062JMES1131

Li, H., Chandrashekhara, K., Komaragiri, S., Lekakh, S. N., \& Richards, V. L. (2014). Crack prediction using nonlinear finite element analysis during pattern removal in investment casting process. Journal of Materials Processing Technology, 7, 1418-1426. http://dx.doi.org/10.1016/j.jmatprotec.2014.02.010

Onuh, S. O., \& Yusuf, Y. Y. (1999). Rapid prototyping technology: Applications and benefits for rapid product development. Journal of Intelligent Manufacturing, 10, 301-311. ISSN: 09565515(20).

Pham, D. T., \& Gault, R. S. (1998). A comparison of rapid prototyping technologies. International Journal of Machine Tools and Manufacture, 38(10-11), 1257-1287. ISSN: 08906955

Singh, R., \& Singh, J. P. (2009). Comparison of rapid casting solutions for lead and brass alloys using three-dimensional printing. Proceedings of the Institution of Mechanical Engineers, Part C: Journal of Mechanical Engineering Science, 223(9), 2117-2123. http://dx.doi.org/10.1243/09544062JMES1387

Sun, C., Shang, W., Zhou, J., \& Li, B. (2014). Numerical simulation and process optimization of superalloy integral precision investment casting diffuser. Cailiao Kexue yu Gongyi. Material Science and Technology, 22, 100-104. ISSN: 10050299

Vaezi, M., Safaeian, D., \& Shakeri, M. (2011). Integration of reverse engineering and rapid technologies for rapid investment casting of gas turbine blades: A comparison between applicable rapid technologies for blade rapid investment casting was conducted and reported in this paper. Virtual and Physical Prototyping, 6, 225-239. http://dx.doi.org/10.1080/17452759.2011.631173

Vdovin, R. A. (2012). 3D virtual simulation and casting process optimization of part GTE "swirler of II duct" with using computer technologies. Vestnik of the Samara State Aerospace University, 3-3(34). 115-120. ISSN: $1998-6629$

Yan, Y., Li, S., Zhang, R., Lin, F., Wu, R., Lu, Q., Xiong, Z., \& Wang, X. (2009). Rapid Prototyping and Manufacturing Technology: Principle, Representative Technics, Applications, and Development Trends. Tsinghua Science and Technology, 14, 1-12. http://dx.doi.org/10.1016/S1007-0214(09)70001-X

\section{Copyrights}

Copyright for this article is retained by the author(s), with first publication rights granted to the journal.

This is an open-access article distributed under the terms and conditions of the Creative Commons Attribution license (http://creativecommons.org/licenses/by/3.0/). 